\title{
Assessment of Pelvic Organ Prolapse by Pelvic Organ Prolapse Quantification Technique Among Pre-operative Patients
}

\author{
Pradhan T, Regmi MC, Rai R, Bhatta R, Rijal P, Uprety DK
}

Department of Obstetrics and Gynaecology, BP Koirala Institute of Health Sciences, Dharan.

\begin{abstract}
Aims: This was performed to examine pelvic organ prolapse using POP-Q technique and correlate pre-existing urinary symptoms with segments of pelvic organ prolapse.

Methods: All patients admitted with pelvic organ prolapse were included. Patients were asked regarding any concomitant urinary symptoms and then all patients were examined by POP-Q technique and correlation of urinary symptoms was done with various segments of pelvic organ prolapse.

Results: Eighty patients were studied in one year duration. Majority of patients had presented with stage 4 prolapse (58.8\%). Majority of patients had urinary symptoms among which $87.5 \%$ had increased urinary frequency, $88.8 \%$ had dysuria, $65 \%$ had stress urinary incontinence (SUI), $72.5 \%$ had incomplete evacuation. Dysuria and SUI was found to have significant correlation with anterior segment prolapse $(\mathrm{p}<0.05 \%)$.
\end{abstract}

Conclusions: Site specific measurements by POP-Q system showed anterior segment prolapse to be more and were significantly associated with various urinary symptoms.

Keywords: pelvic organ prolapse, POP-Q, urinary symptoms.

\section{INTRODUCTION}

Pelvicorgan prolapse (POP) is a bulge or protrusion of pelvic organs and their associated segments into or through the vagina. In Nepal, prevalence of pelvicorgan prolapse is high. It exceeds 10 percent of women in reproductive age group and 24 percent in women of age group between 45 to 49 years. ${ }^{1}$ Among women diagnosed with POP, 69.1 percent had first degree prolapse and remaining 30.9 percent had second and third degree prolapse. ${ }^{2}$ Pelvic organ prolapse possesses major suffering in women's life, psycho-socially, economically and physically.

Pelvic organ prolapse quantification technique (POP-Q) was introduced by International Contintence

\section{CORRESPONDENCE}

Dr Tarun Pradhan

Department of Obstetrics and Gynaecology, BP Koirala Institute of Health Sciences, Nepal. E-mail: dr_tarun802@hotmail.com

Phone: +977-9841305611
Society as a site-specific measuring technique of pelvic organ prolapse. It measures using definite anatomical landmark, minimizing inter-observer variability and making it more scientific while assessing patients during follow up. ${ }^{3,4}$ So far, few studies have been carried out studying pelvic oragn prolapse using POP-Q technique and correlation with urinary symptoms in Nepalese population. Annually, 100 or more patients with pelvic organ prolapse are assessed and operated in our department, so the demand of getting along with new system is rife, because it influences the management.

This study attempted to measure all patients admitted with pelvic organ prolapse by POP-Q technique pre-operatively and stage the prolapse according to

The papers in this journal are published under the terms of the Creative Commons Attribution License. Users are allowed to read, download, copy, distribute, print, search, or link to the full texts of the articles in this journal without asking prior permission from the publisher or the author. 
ordinal staging ${ }^{3}$ and also correlate the measurements with existing urinary symptoms.

\section{METHODS}

This was a descriptive study in patients who were admitted in Department of Obstetrics and Gynaecology, BP Koirala Institute of Health Sciences (BPKIHS). The study was conducted from $15^{\text {th }}$ February 2009 to $15^{\text {th }}$ February 2010 after getting IRB approval. All patients admitted and declared fit for surgery with diagnosis of pelvic organ prolapse after taking informed consent were included. Patients with abdomino-pelvic mass and those who were unfit for surgery; were excluded. Women were inquired regarding their urinary symptoms as per performa and were examined with sterile measuring metal scale calibrated in centimetres with sterile gloves, sterile sims speculum, and sterile volsellum. Patients were examined in dorsal position before and after evacuation of bladder. Demonstration of pelvic organ prolapse was done by Valsalva manoeuvre or by traction. Site-specific measurements of various site of prolapse were done using POP-Q technique, the measurements were then plotted in a three by three grid and ordinal staging was done.

The Pelvic Organ Prolapse Quantification (POP-Q) score is used to describe, quantify and stage pelvic floor support. The measurements were taken from six different points in the vagina and the hymen, first at rest and then at maximum effort during the Valsalva maneuver. These six points are located above the hymen in women without a prolapse, and their distance from the hymen was measured negatively when they remain above the hymen during the maneuver. The distance was measured positively when the prolapse protrudes past the hymen, such that the points are located below the hymen, during the Valsalva maneuver. Of these six points two are located on the anterior vaginal wall ( $\mathrm{Aa}$ and $\mathrm{Ba}$ ), two are located onthe posterior vaginal wall (Ap and $\mathrm{Bp}$ ), one is located at the anterior lip of the cervix or, in women who had a hysterectomy, at the vaginal cuff (C) and one is located in the posterior fornix inwomen who have not had a hysterectomy (D). The genital hiatus (Gh) and the perineal body $(\mathrm{Pb})$ were also measured at rest and during the Valsalva maneuver. Total vaginal length (TVL), however, was only measured at rest.

By definition, Aa is located $3 \mathrm{~cm}$ above the hymen along the midline on the anterior vaginal wall. The range of the measurement for the distance of Aa to the hymen during the Valsalva maneuver is $-3 \mathrm{~cm}$ (normal) to $+3 \mathrm{~cm}$ when a defect in the anterior vaginal wall is present. $\mathrm{Ba}$ is located most distally between $\mathrm{Aa}$ and C. In women with no defect in the anterior vaginal wall, $\mathrm{Ba}$ is also at $-3 \mathrm{~cm}$ from the hymen. In women with a defect in the anterior vaginal wall, the value is between $-3 \mathrm{~cm}$ and, in the most severe cases of prolapse, the entire TVL. By definition, Ap is located $3 \mathrm{~cm}$ above the hymen on the posterior vaginal wall. The range of the measurement for the distance of Ap to the hymen during the Valsalva maneuver is -3 $\mathrm{cm}$ (normal) to $+3 \mathrm{~cm}$. Bp is located most distally between $\mathrm{Ap}$ and $\mathrm{C}$. In women with no defect in the posterior vaginal wall, $\mathrm{Bp}$ is at $-3 \mathrm{~cm}$ from the hymen. In women with a defect in the posterior vaginal wall, the value is between $-3 \mathrm{~cm}$ and, in the most severe cases of prolapse, the entire TVL.The measurements were then recorded in a table so that comparisons could be made pre- and post-surgery.

The data were analysed using SPSS. Median range was calculated for measurement obtained from POP-Q examination. Pearson's correlation and fisher's exact test were done for evaluating relation between urinary symptoms and various POP-Q measurements.

\section{RESULTS}

Eighty patients were included in the study and their demographic information at admission is as shown in Table1.

Table 1. Demographic information of the study population $(n=80)$.

\begin{tabular}{lll}
\hline Characteristics & & Number (\%) \\
\hline Age (yrs) & $20-40$ & $14(17.5)$ \\
& $41-60$ & $45(56.3)$ \\
& $>60$ & $21(26.3)$ \\
$\begin{array}{l}\text { Duration of } \\
\text { (yrs) }\end{array}$ & $1-10$ & $53(66.3)$ \\
& $11-20$ & $14(17.5)$ \\
Menopause & $>20$ & $13(16.3)$ \\
& Yes & $59(73.8)$ \\
Smoker & No & $21(26.3)$ \\
& Yes & $19(23.8)$ \\
Chronic cough & No & $61(76.3)$ \\
& Yes & $15(18.8)$ \\
Constipation & No & $65(81.3)$ \\
& Yes & $10(12.5)$ \\
Early & No & $70(87.7)$ \\
resumption of work & Yes & $54(67.5)$ \\
& No & $26(32.6)$ \\
\hline
\end{tabular}


Majority of the patients were above 40 years of age and 73.8 percent were menopausal.The duration of prolapse was less than 10 years in 53 patients, of which 23.8 percent gave history of smoking and 18.8 percent gave historyof chronic cough. Interestingly, 67.5 percent of the patients had resumed house-hold activity with in one week post-partum.

Table 2. Distribution of sites of prolapse segments outside the hymenby POP-Q measurements $(n=80)$.

\begin{tabular}{ll}
\hline POP-Q & $\begin{array}{l}\text { Segment outside the } \\
\text { hymen (\%) }\end{array}$ \\
\hline $\mathrm{Aa}$ & 91.3 \\
$\mathrm{Ba}$ & 96.3 \\
$\mathrm{C}$ & 98.8 \\
$\mathrm{Ap}$ & 45.0 \\
$\mathrm{Bp}$ & 91.3 \\
$\mathrm{D}$ & 78.0 \\
\hline
\end{tabular}

Table 2 shows distribution of POP-Q measurements, those found to beoutside the hymen. We categorised the POP-Q measurements in two: (a) when measurements are inside the hymen and (b) when measurements are outside the hymen. Majority of measurements showed segments outside the hymen and in addition anterior vaginal segments decent were more than posterior segment decent.

Table 3. Correlation of urinary symptoms with various sites of POP as measured by POP-Q technique $(\mathrm{n}=\mathbf{8 0})$.

\begin{tabular}{llllllc}
\hline Symptoms & $\mathbf{A a}$ & $\mathbf{B a}$ & $\mathbf{C}$ & $\mathbf{A p}$ & $\mathbf{B p}$ & $\mathbf{D}$ \\
\hline $\begin{array}{l}\text { Increased } \\
\text { frequency }\end{array}$ & $0.004^{*}$ & $0.001 *$ & 0.125 & 1.0 & 1.0 & 0.680 \\
Dysuria & $0.002^{*}$ & $0.001 *$ & 0.113 & 1.0 & 0.581 & 0.676 \\
SUI & $0.048^{*}$ & $0.040^{*}$ & 0.350 & 0.488 & 1.0 & 0.776 \\
$\begin{array}{l}\text { Incomplete } \\
\text { evacuation }\end{array}$ & 0.086 & 0.019 & 0.275 & 1.0 & 1.0 & 0.769 \\
$\begin{array}{l}\text { Retention } \\
\text { of urine }\end{array}$ & 0.181 & 0.557 & 1.0 & $0.047 *$ & 0.667 & 1.0 \\
\hline
\end{tabular}

$*=p<0.05$ as significant

Table 3 shows p-value of correlation of urinary symptoms with various measurements of pelvic organ prolapse by POP-Q technique. P- value less than 0.05 was considered significant.
Table 4 shows distribution of stage of prolapse.

\begin{tabular}{ll}
$\begin{array}{l}\text { Table 4. Distribution of ordinal staging of POP } \\
(\mathbf{n}=\mathbf{8 0}) .\end{array}$ \\
\hline Ordinal Stage & Number $(\%)$ \\
\hline 2 & $12(15.0)$ \\
3 & $21(26.3)$ \\
4 & $47(58.8)$ \\
\hline
\end{tabular}

\section{DISCUSSION}

In the study, all our patients were questioned verbally before examination regarding set of urinary symptoms. Majority had increased urinary frequency 70 out of $80(87.5 \%)$, dysuria 71 of $80(88.8 \%)$, SUI 52 of $80(65 \%)$, incomplete evacuation 58 of 80 (72.5\%), but comparatively small number of patients had symptoms of urinary retention 22 of 80 (27.5\%) $\{$ Table 3$\}$.

Similar to our study, a study conducted by Marijke et $\mathrm{al}^{5}$ found significant association between urinary symptoms and POP-Q anatomical notations. Presence of urge incontinence was found to have significant association with lowest point of upper anterior vaginal wall decent. They also concluded that anterior compartment prolapse was related with urge urinary incontinence and posterior compartment prolapse was related with bowel disorder. But our results differed from Bradley et $\mathrm{al}^{6}$ in which most of the significant associations were with obstructive bowel disorder, feeling of anal prolapse, manual evacuation of stool per vaginum and per anum. They also found that lower portion of anterior vaginal wall decent was associated with bladder pain and obstructive symptoms but with out urge incontinence. In our survey there was no significant association with obstructive urinary symptoms like retention of urine.

In this study, the stage of POP started from stage 2 to 4 as $15 \%, 26.3 \%$ and $58.8 \%$ respectively (Table 4). Most of the POP was of stage 4 with dysuria and stress urinary incontinence showing significance with increasing stage of prolapse. In contrast to this study Marijke et $\mathrm{al}^{5}$ had no correlation with stages of prolapse with urinary symptoms but they had association with feeling of bulge or dragging sensation. In addition, Digesue et $\mathrm{al}^{7}$ showed poor correlation of urinary symptoms except for feeling of incomplete evacuation and need of straining during micturation with pelvic organ prolapse. But there was a significant association with posterior segment descent with bowel symptoms. In contrast, this study had very poor correlation with obstructive bowel symptoms. In study done by Swift et $\mathrm{al}^{8}$ also 
women with pelvic organ prolapse with the leading edge of the prolapse beyond the hymenal remnants (some stage II and all stage III) had increased urinary symptoms.

\section{CONCLUSIONS}

POP-Q technique in assessment of pelvic organ prolapse was anatomically site specific and was with less inter-observer variation. Anterior segment prolapse asmeasured by POP-Q technique had significant association with various urinary symptoms. Therefore adoption of POP-Q technique in examination of pelvic organ prolapse marks step towards using new system approved and encouraged worldwide.

\section{REFERENCES}

1. Gurung G, Rana A, Amatya A, Bista KD, Joshi AB, Sayami J. Pelvic organ prolapse in rural Nepalese women of reproductive age groups: what makes it so common? $\mathrm{N} \mathrm{J}$ Obstet Gyaecol. 2007;2(2):35-41.

2. Dhital R, Otsuka K, Poudel KC, Yasuoka J, Dangal G, Jimba M. Improved quality of life after surgery for pelvic organ prolapse in Nepalese women. BMC Women's Health. 2013;13:22. [cited 2013 December 10]. Available from http://www.biomedcentral.com/1472-6874/13/22. doi:10.1186/1472-6874-13-22

3. Bump RC, Mattiasson A. The standardization of terminology of female pelvic organ prolapse and pelvic floor dysfunction. Am J Obstet Gynecol. 1996;175:10-7.
4. Persu C, Chapple CR, Cauni V, Gutue S, Geavlete P. Pelvic organ prolapse quantification system (POP-Q): a new era in pelvic prolapse staging. J Med Life. 2011;4(1):75-81.

5. Marijke C, Hove S, Annelies L, Goudzwaard P, Marinus JC, Regine PM, et al. The prevalence of pelvic organ prolapse symptoms and sign and their relation with bladder and bowel disorder in a general female population. Int Urogynecol J. 2009;20(9):1037-45.

6. Bradley CS, Zimmerman MB, Wang Q, Nygaard IE. Vaginal decent and pelvic floor symptom in post-menopausal women: a longitudinal study. Obstet Gynecol. 2008; $111 ; 1148-53$

7. Digesu GA, Chaliha C, Salvatore S, Hutchings A, Khullar V. The relationship of vaginal prolapse severity to symptoms and quality of life. Int J Obstet Gynaecol. 2005;112:971-6.

8. Swift SE, Tate SB, Nicholas J. Correlation of symptoms with degree of pelvic organ support in a general population of women: what is pelvic organ prolapse? Am J Obstet Gynecol. 2003;189:372-9.

9. Zimmerman CW. Pelvic organ prolapse: basic principles. In: Rock JA, Jones HW, editors. Te-Linde's Operative Gynaecology. 10th ed. Philadelphia: Lippincott Williams and Wilkins; 2008. p. 854-73.

10. Richter HE, Varner RE. Pelvic organ prolapse. In: Berek JS, editor. Berek and Novak's Gynecology. 14th ed. USA: Lippincott Williams and Wilkins;2007.p.897-934.

11. Bonetti TR, Eepelding A, Pathak LR. Reproductive morbidity: a neglected issue? A report of a clinic based study held in far-western Nepal. Kathmandu, Nepal: Ministry of health, GTZ and UNFPA; 2002. 